\title{
Exploring tarnished daguerreotypes with synchrotron light: XRF and $\mu$-XANES analysis
}

\author{
M. S. Kozachuk ${ }^{1 *}$, T. K. Sham ${ }^{1 *}$, R. R. Martin ${ }^{1}$, A. J. Nelson ${ }^{1,2}$ and I. Coulthard ${ }^{3}$
}

\begin{abstract}
We report on the elemental and chemical characterization of tarnish on a historic daguerreotype plate. Scanning electron microscopy (SEM) and energy dispersive $X$-ray (EDX) spectroscopy reveal the presence of $\mathrm{C}, \mathrm{O}, \mathrm{Na}, \mathrm{K}, \mathrm{P}, \mathrm{Cl}$, $\mathrm{Hg}, \mathrm{Ag}, \mathrm{Cu}, \mathrm{S}$ and $\mathrm{Au}$. Synchrotron based X-ray absorption near edge structure (XANES) spectroscopy, together with two-dimensional X-ray fluorescence (XRF) microscopy, provide information beyond the elemental distribution and speciation of the daguerreian tarnish features, revealing the presence of $\mathrm{NaCl}, \mathrm{KCl}_{1} \mathrm{HgCl}_{2}, \mathrm{HgSO}_{4}, \mathrm{CuS}$, and $\mathrm{Ag}_{2} \mathrm{~S}$ on the surface. Through the application of synchrotron XRF, the distributions of $\mathrm{Ag}$ and $\mathrm{S}$ were found to be inversely correlated. This suggests a preferential accumulation of $S$ within high-density particle regions. Spectroscopic investigation at different regions within the XRF image showed that blemish regions contained degradation products such as $\mathrm{NaCl}$ and $\mathrm{KCl}$ with $\mathrm{AgCl}$ noted in the surrounding regions. The observation of $\mathrm{Cu}$ on the surface, in the form of CuS, may either be a result of Cu diffusing through grain boundaries and/or holes in the Ag, or from the accretion of Cu salts, such as basic sodium copper carbonate, from the deterioration of the above cover glass. Silver halides ( $\mathrm{AgCl}, \mathrm{AgBr}$ and $\mathrm{Agl}$ ) were also detected with XANES. This may be the result of either environmental conditions or from residual products from the production process of the plate. These results point to the interaction between deterioration products from the cover glass with the daguerreotype surface as one, but not the only, source of the tarnish.
\end{abstract}

Keywords: Daguerreotypes, X-ray fluorescence microscopy, X-ray absorption near-edge structure, Scanning electron microscopy, Elemental dispersive X-ray spectroscopy, Surface topology, Tarnish, Cover glass

\section{Introduction}

Eighteen thirty-nine saw the invention of the first recognized, commercial form of the photograph, the daguerreotype, which was named after its inventor, Louis-Jacques-Mandé Daguerre. The daguerreotype process was used to document individuals and landscapes for approximately 30 years; these images are now important objects of historic significance. The fabrication of daguerreotypes has been previously reported $[1,2]$. The daguerreian image is the result of reflection and refraction of light off image particles that vary in shape and distribution. This yields the range of gray tones that typify

\footnotetext{
*Correspondence: mkozachu@uwo.ca; tsham@uwo.ca

${ }^{1}$ The Department of Chemistry, The University of Western Ontario, 1151

Richmond Street, London, ON N6A 5B7, Canada

Full list of author information is available at the end of the article
}

daguerreotypes [3]. Image particle size, shape, and density (defined as the number of particles per surface area) were dependent on the relative light intensity and exposure [4, p. 122]. Areas subjected to a relatively greater light intensity (i.e., highlight regions) produced image particles relatively uniform in structure and density while little to no exposure (i.e., dark regions) produced image particles variable in size, shape, and low surface density. Colour tones may also be imparted by variations in plate preparation and processing conditions, which will result in the appearance of warm tones, solarization blues, etc.

The conservation of these historic artifacts is a challenge for conservators and scientists. Daguerreotypes are prone to corrode under ambient conditions resulting in the production of metal oxides and sulfides that generate haze and spots across the surface [4, p. 162]. Sulfur and chlorine are the two elements with the greatest 
association with daguerreotype image deterioration in the forms of silver sulfide [5] and silver chloride [6], respectively. Several analytical techniques [3, 7-10] have been used to further the understanding of the tarnish composition for conservation, preservation, storage, and display of these artifacts. Currently, there is no clear explanation for the origin of tarnish features, nor is there a consensus on the most effective conservation technique. The goal of the present study is to better understand the origin and composition of the tarnish features. This study is part of an ongoing analysis of the surface chemistry of daguerreotypes [11].

Previous analysis [1-11] has suggested that one possible source of the tarnish could be the deterioration of the cover glass used to protect the daguerreotypes from chemical and/or atmospheric conditions, dust and debris, or from mechanical damage. For example, Barger [12] suggested that deterioration of the cover glass as well as the geometry and composition of the frame might lead to deterioration of daguerreotypes. Patchy areas of discolouration, distinct clusters of amber coloured "crystals", cloudiness, and sticky droplets (termed "weeping" glass) are just a few features observed on 19th century cover glasses [12]. Cover glass decomposition has been suggested to lead to the deposition of $\mathrm{Na}_{2} \mathrm{SO}_{4}, \mathrm{BaSO}_{4}$, $\mathrm{NH}_{4} \mathrm{Br}, \mathrm{Ag}, \mathrm{AgCl}, \mathrm{Ag}_{3} \mathrm{PO}_{4}, \mathrm{HCOONa}$, and $\mathrm{Cu}_{2} \mathrm{O}$. Such deterioration is the result of alkali ions in the glass network reacting with water vapour and other airborne gasses [12]. For example, one route of 19th century glass corrosion involves the migration of $\mathrm{Na}^{+}$and $\mathrm{K}^{+}$to the surface through an ion-exchange reaction by hydrogen ions, a reaction that is dependent on the moisture content of the atmosphere $[13,14]$. Apart from daguerreotypes, glass deterioration is of concern to conservation scientists working within the cultural heritage sector on stained glass objects and glass beads [13-16].

Previous analyses have not been conclusive and there are still unknown phases (i.e., chemical and physical properties) of corrosion products that require examination. Importantly, such unknown phases and chemical composition of daguerreotype tarnish could negatively impact conservation efforts. Through the application of synchrotron X-ray analysis, various forms of daguerreotype deterioration are examined here including the effects of cover glass corrosion on the image surface. While the original cover glass was not available for analysis, there is ample documentation in the literature regarding the physical and optical qualities of glass degradation features relevant to the tarnish regions analyzed in this study. Through synchrotron X-ray analysis, particularly $\mathrm{X}$-ray fluoresce (XRF) microscopy and X-ray absorption near edge structure (XANES) spectroscopy capabilities, the chemical environment of tarnished areas on the daguerreotype surface was characterized. The objective here was to determine the composition and distribution, and therefore the origin, of the tarnish features observed on a daguerreotype from the National Gallery of Canada (Ottawa, Canada) in order to develop conservation strategies. The combination of XRF maps with micro-XANES spectra using a microbeam enabled the simultaneous two-dimensional visualization of degradation products on the daguerreian surface, along with tarnish speciation and characterization at various locations on the surface. Scanning electron microscopy energy dispersive X-ray spectroscopy (SEM-EDX) and optical microscopy were used to determine the morphology of these features.

\section{Materials and methods \\ Historical sample}

The National Gallery of Canada (NGC) Study Collection provided the 19th century daguerreotype examined in this study (Fig. 1) which shows a portrait of a seated woman. This plate was chosen as it demonstrates a number of features that are characteristic of daguerreotype tarnish. The plate would have been mounted between a brass mat and a cover glass, which were bound together with a paper tape and an adhesive. These components were then placed within a small case of leather and wood. It is not known if any previous conservation treatments were applied at any time prior to being received by the NGC. In addition, it has not been treated or cleaned since being in the NGC collection. The sample was examined as received without any preparation. The entire plate was examined visually and with optical microscopy. Regions of interest where the greatest amount of degradation was observed were examined with SEM, EDX, XRF and micro-XANES.

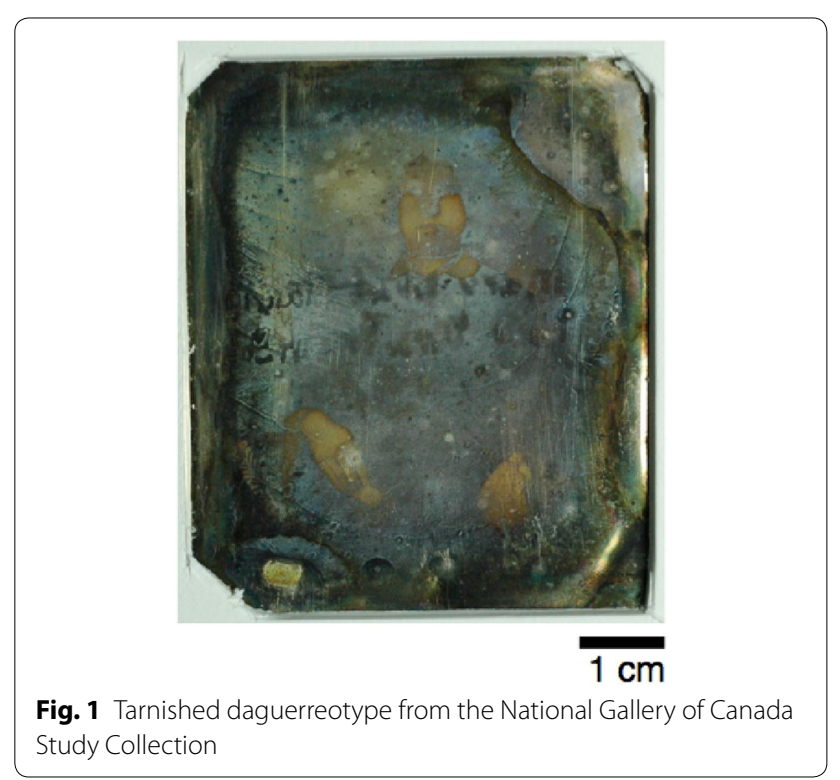




\section{Synchrotron analysis}

The medium energy X-ray microprobe end station at the SXRMB (06B1-1) line of the Canadian Light Source (CLS) synchrotron was used to collect the two-dimensional XRF maps and the XANES spectra [17]. The beamline is at a bending magnet source and features a pre-mirror (collimation), double crystal monochromator (fixed exit beam), and a post-mirror configuration, specifically design to provide tender X-rays $(1.8-8 \mathrm{keV})$.

XANES is the spectroscopy of absorption edges. An abrupt jump (edge) in the absorption coefficient appears in the X-ray absorption spectrum (absorption vs. incident photon energy) when the incident X-ray has sufficient energy to excite a core electron (overcome the binding energy) in an element in a chemical environment to previously unoccupied electronic states. Since the binding energy of all the core levels of elements is unique to the element, absorption features at the edge (XANES) are unique to the element and its neighboring atoms.

A tunable X-ray source can excite a particular element preferentially by tuning the X-ray energy to above the absorption edge of the element of interest, enhancing the yield of fluorescence X-ray from the elements of interest. The microbeam was produced downstream with Kirkpatrick-Baez (KB) micro-focusing mirrors. The sample stage is housed in a separate chamber downstream, equipped with a $\mathrm{Si}(\mathrm{Li})$ drift detector (SDD), a CCD camera and a 3 -axis $(\mathrm{X}, \mathrm{Y}$ and $\mathrm{Z})$ sample stage. A micro-ion chamber is placed in between the KB mirror chamber and the sample chamber, for beam alignment and monitoring. The spot size of the beam at the specimen is $\sim 10 \mu \mathrm{m} \times 10 \mu \mathrm{m}$. The SDD has a moderate energy resolution of $\sim 130 \mathrm{eV}$, sufficient to separate all the fluorescence $\mathrm{X}$-rays of interest in this analysis.

The beam was monochromatized by a $\mathrm{Si}(111)$ double crystal monochromator; silver $(\mathrm{Ag})$, chlorine $(\mathrm{Cl})$, and sulfur (S) XANES were collected in fluorescence (FLY) mode. The $\mathrm{Ag} \mathrm{L}_{3}$-edge XANES was collected with a $2.00 \mathrm{eV}$ step size below, $0.15 \mathrm{eV}$ step size at, and $0.75 \mathrm{eV}$ step size above the edge. The $\mathrm{Cl} \mathrm{K}$-edge XANES was collected with the same set of parameters. The S K-edge was collected with a $2.00 \mathrm{eV}$ steps below, $0.20 \mathrm{eV}$ step at, and a $0.75 \mathrm{eV}$ step above the edge. XANES spectra were compared to standards listed in Table 1. The standards used in this study, aside from the silver-gold alloys, were obtained through Sigma-Aldrich. The Au-Ag alloys were made with repeated arc melting in argon of stoichiometric amount of each component and were thoroughly characterized [27]. The number of scans collected for the XANES analysis of the daguerreotypes depended on the intensity and signal to noise ratio of the signal. This varied between locations within and between the two plates (Additional file 1: Figure S1).
Table 1 List of standards used for XANES analysis

\begin{tabular}{lll}
\hline $\begin{array}{l}\text { Element } \\
\text { of interest }\end{array}$ & Standards & $\begin{array}{l}\text { Edge jump } \\
\text { analyzed }\end{array}$ \\
\hline $\mathrm{Ag}$ & $\mathrm{Ag}_{1} \mathrm{Ag}_{95} \mathrm{Au}_{5}, \mathrm{Ag}_{75} \mathrm{Au}_{25}, \mathrm{Agl}, \mathrm{AgCl}, \mathrm{AgBr}$, & $\mathrm{L}_{3}$-edge \\
& $\mathrm{Ag}_{2} \mathrm{O}_{1} \mathrm{Ag}_{2} \mathrm{~S}, \mathrm{AgNO}_{3}$ & \\
$\mathrm{Cl}$ & $\mathrm{AgCl}, \mathrm{NaCl}, \mathrm{KCl}, \mathrm{HgCl}_{2}, \mathrm{Au}\left(\mathrm{SMe}_{2}\right) \mathrm{Cl}$ & $\mathrm{K}$-edge \\
$\mathrm{S}$ & $\mathrm{Ag}_{2} \mathrm{~S}_{2} \mathrm{Na}_{2} \mathrm{SO}_{4}, \mathrm{Na}_{2} \mathrm{SO}_{3}, \mathrm{CuS}_{2} \mathrm{Cu}_{2} \mathrm{~S}, \mathrm{HgSO}_{4}$, & $\mathrm{K}$-edge \\
& $\mathrm{Na}_{2} \mathrm{~S}_{2} \mathrm{O}_{3} \cdot 5 \mathrm{H}_{2} \mathrm{O}$ & \\
\hline
\end{tabular}

The Athena software package [18] was used to calibrate, background subtract, normalize, and average all spectra. The inflection point at the edge was determined by taking the first derivative of each spectrum as well as setting the tangent slope to zero in the second derivative spectrum following the procedure outlined by Ravel [19]. When appropriate, the Athena software was used to perform a linear combination fit (LCF) to provide semiquantitative weight percent (wt. \%) values from the normalized $\mu(E)$ daguerreotype spectra in terms of spectra from standards. Here, two or more standard spectra are fit to the spectrum in question, which has already undergone data processing. The standards are constrained to $100 \%$ of the unknown by having the weight for the last spectrum be one minus the sum of the other weights. Therefore, if three standards are used, the first two would have weights $\mathrm{x}$ and $\mathrm{y}$ and the third would have weight $1-x-y$. X and $y$ are then varied to obtain an optimal fit. Each standard spectrum is interpolated onto the energy grid of the unknown spectrum when the fit is performed. Analyses were conducted over an energy range of $-20 \mathrm{eV}$ below and $+30 \mathrm{eV}$ above the edge. Uncertainty is determined through subtracting between the original data and the fitted spectrum. This analysis can determine the species percent contribution of standard in a heterogeneous material.

X-ray fluorescence images were collected for silver, mercury, chlorine, phosphorus, iodine, and sulfur. Scanning parameters are outlined in Table 2. X-ray fluorescence maps were created and analyzed using the SMAK software program [20]. All XRF maps were normalized to $\mathrm{I}_{\mathrm{o}}$.

\section{SEM-EDX}

Both plates were examined with the LEO (Zeiss) 1540XB FIB/SEM instrument at the Western Nanofabrication facility. Topographic imaging was performed at a primary electron beam energy of $1 \mathrm{kV}$ with a working distance of 4 and $5.6 \mathrm{~mm}$. Energy dispersive X-ray spectroscopy examination was conducted with the SEM's Oxford Instruments $\mathrm{X} \max 50$ detector and analysis was performed with INCA analysis software. ImageJ software was used for image particle density calculation [21]. 
Table 2 Scanning parameters for XRF maps collected from the NGC daguerreotype, the excitation energy is above the $\mathrm{L}_{3}$-edge of $\mathrm{Ag}(3351 \mathrm{eV})$ and the K-edges of $\mathrm{S}$ $(2473 \mathrm{eV})$ and $\mathrm{Cl}(2822 \mathrm{eV})$

\begin{tabular}{lllll}
\hline Figures & $\begin{array}{l}\text { Incident } \\
\text { energy }(\mathrm{eV})\end{array}$ & $\begin{array}{l}\text { Pixel size } \\
(\boldsymbol{\mu} \mathbf{m})\end{array}$ & $\begin{array}{l}\text { Dwell time } \\
(\mathbf{s})\end{array}$ & $\begin{array}{l}\text { Scan size } \\
(\boldsymbol{\mu m})\end{array}$ \\
\hline Fig. 5 & 3950 & $15 \times 15$ & 1.0 & $1600 \times 1000$ \\
Fig. 6 & & $40 \times 40$ & 1.0 & $2000 \times 1200$ \\
Fig. 7 & & $10 \times 10$ & 1.0 & $600 \times 550$ \\
\hline
\end{tabular}

\section{Optical microscopy}

Optical microfocus images and feature profiles of specific tarnish features were acquired using a Leica DVM6 digital optical microscope with Leica Application Suite X processing software with the Department of Chemistry at The University of Western Ontario.

\section{Results and discussion}

The section is arranged in two segments as follows. First optical microscopy and SEM were used to identify image particles associated with the tone and brightness of selected regions, as well as tarnish features. SEM-EDX was used to establish element distribution. Second, SR$\mathrm{XRF}$ imaging was used to further elucidate the element distribution followed by micro-XANES to study the detailed surface chemistry.

\section{Morphology of daguerreotype surface from SEM}

The daguerreotype (Fig. 1) revealed patches of white haze across the majority of the portrait, masking the entirety of the woman's body. This type of haze, typical for tarnished daguerreotypes, has been previously attributed to $\mathrm{AgCl}$ [6], a conclusion that was confirmed with XANES and EDX analysis in this study. Under this photolytic tarnish, the characteristic image particles of each region can be seen with SEM. The particles are small and densely packed for the highlight region and unequally dispersed and shaped image agglomerates for the dark region (Fig. 2). The presence of these larger image particles confirms that the woman's shoulder to be a dark region, despite the white haze that masks the image. While some smaller particles were observed in the shadow region alongside the image agglomerates, which are not expected in the shadow region, they may be the result of the photo-catalyzed reaction to Ag particles from the invasive $\mathrm{AgCl}$ that covers the surface. The majority of the particles within this region correspond in size to the reported values for image particles in mid-tone regions $[4$, p. 120].

The plate (Fig. 1) exhibits a variety of tarnish defects (Fig. 3) including flattened dark circles, white fogging across broad regions of the image, bubbles, and protruding crystalline particles. The presence of red and blue tones suggests the presence of $\mathrm{Ag}_{2} \mathrm{O}$ and $\mathrm{Ag}_{2} \mathrm{~S}$ and/or silver gold sulfide compounds (such as AuAgS or $\mathrm{AuAg}_{3} \mathrm{~S}_{2}$ )

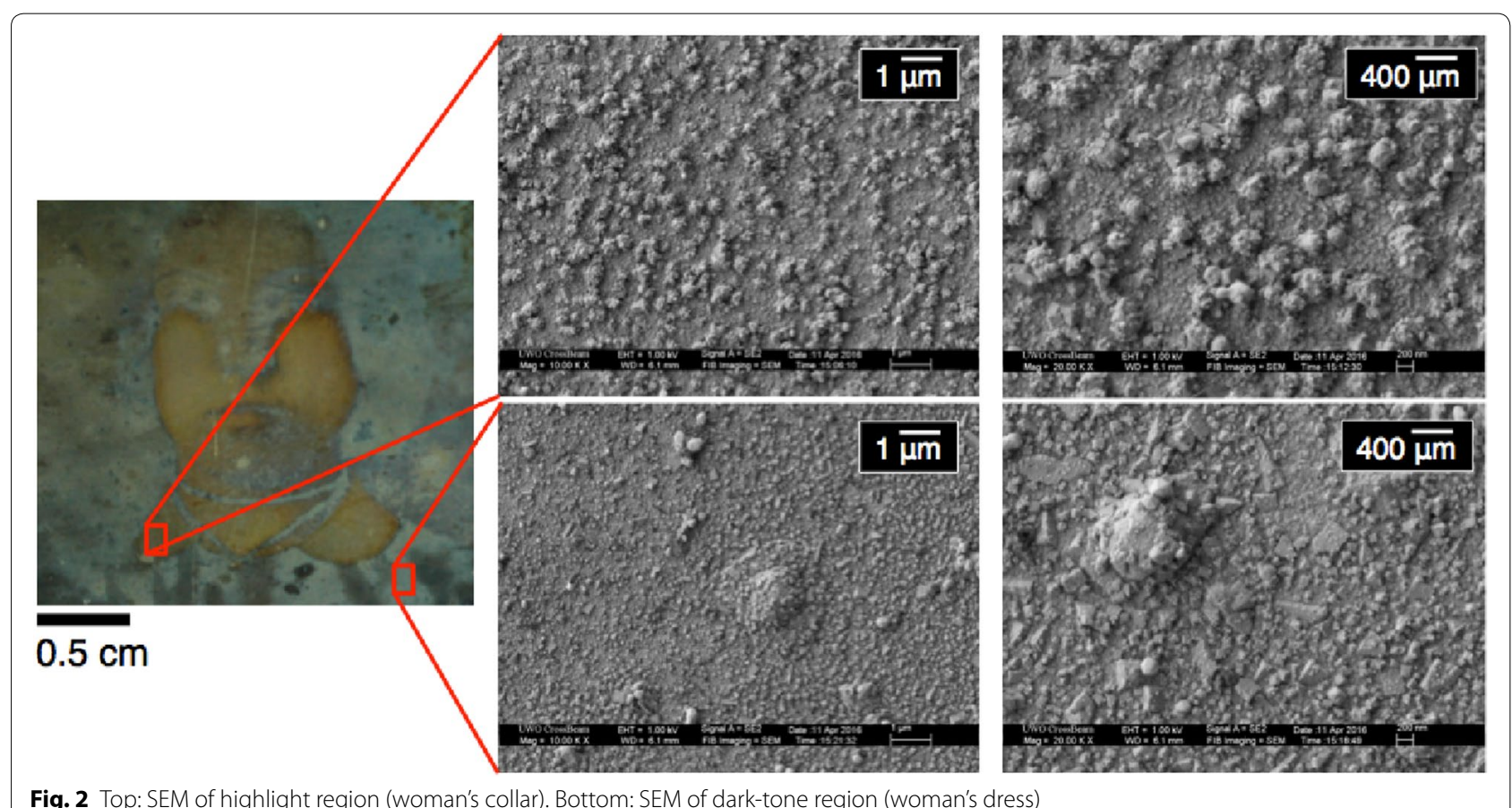

Fig. 2 Top: SEM of highlight region (woman's collar). Bottom: SEM of dark-tone region (woman's dress) 


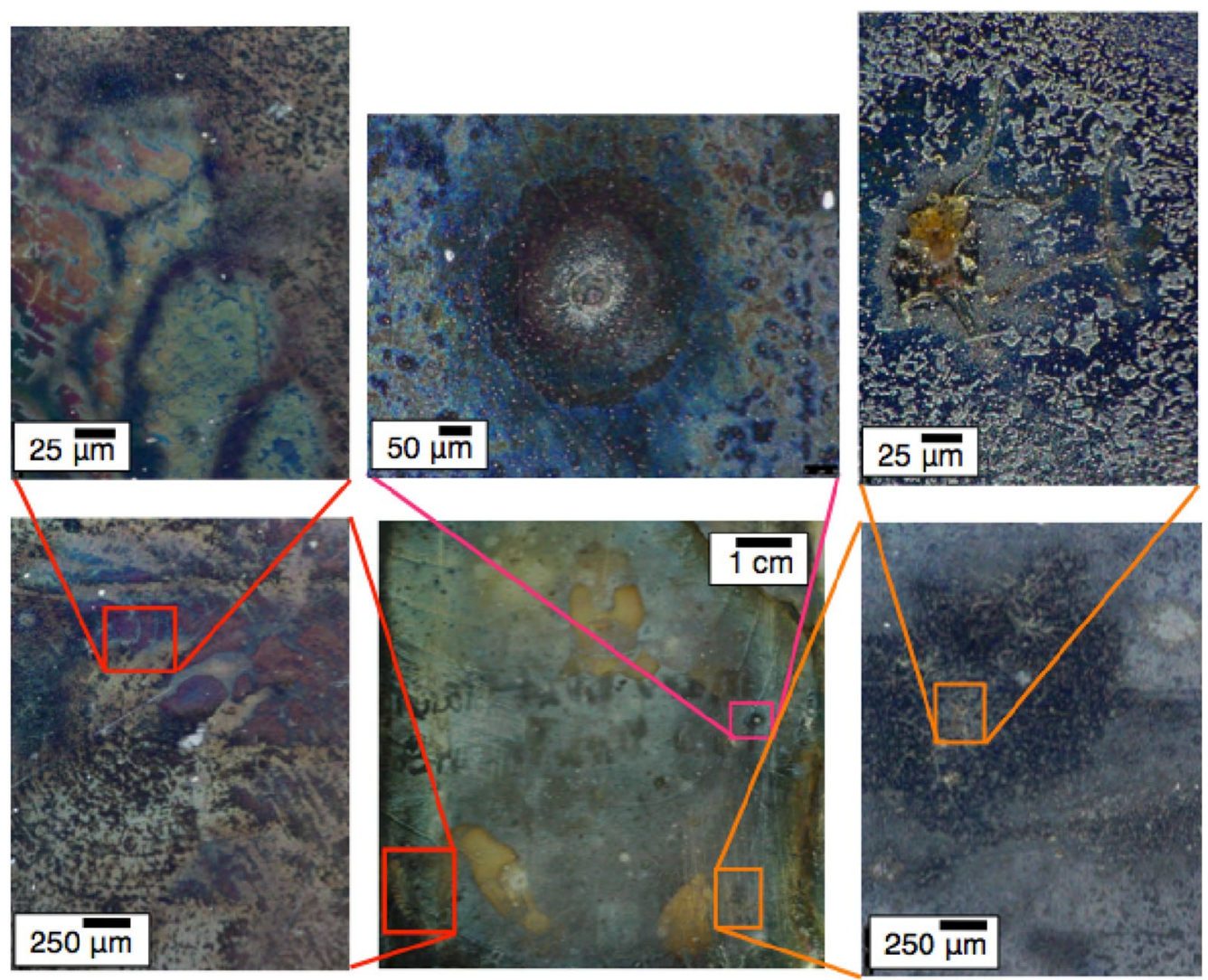

Fig. 3 Optical images of tarnish features of three different regions on the plate

on the surface, respectively $[4$, p. 215,22$]$. This material, when not surrounding a specific defect spot, is concentrated on the exterior border of the plate, a region prone to tarnish from contact with the metal frame of the daguerreotype plate. The presence of bubbles, one of which was analyzed with an X-ray microprobe, will be discussed below (Fig. 6).

Figure 4 shows the SEM and EDX of a tarnished area on the plate, whose center presents a crystalline, petallike structure. These petals, which fold outwards, are rich in $\mathrm{K}$ and $\mathrm{Cl}$. Enrichment of $\mathrm{C}$ is seen at the base and $\mathrm{P}$ is present in hot spots at the edges of the petal features. Oxygen is observed to be associated with the P, suggesting the presence of a phosphate. The $\mathrm{K}$ on the surface may arise from the deterioration of the cover glass under which the daguerreotype was enclosed [13, 23]. Dendrite-like structures containing $\mathrm{K}$ and $\mathrm{P}$ have been previously observed with SEM as a result of leaching from a cover glass that was originally designed to protect the daguerreotype from corrosion [12]. Furthermore, dendrites have been previously observed in non-uniform corrosion on silver surfaces [24]. Another possible source for $\mathrm{K}$ is the production process. Humphrey discusses various uses of $\mathrm{K}$ within the 19th century daguerreotype process: such as the use of dilute potassium cyanide to increase the "brilliancy of the daguerreotype" after the gilding step [25]. The photosensitising step may also be the source for residual $\mathrm{Cl}$ [25]. The presence of $\mathrm{Cl}$ on the daguerreian surface has also been attributed to glass deterioration [25]. As the cover glass was unavailable for a comparative analysis, the origin of $\mathrm{K}$ remains unknown although it is not uncommon to have $\mathrm{K}$ and $\mathrm{Cl}$ in glass.

\section{XRF and micro-XANES analysis}

$\mathrm{X}$-ray fluorescence images (collected at $3950 \mathrm{eV}$ excitation energy, above the $\mathrm{Ag} \mathrm{L}_{3}$-edge, $3351 \mathrm{eV}$ ) of $\mathrm{Ag}, \mathrm{Cl}$, and $\mathrm{S}$ (obtained with partial fluorescence yield of $\mathrm{Ag}$ $\mathrm{L} \alpha$ and $\mathrm{S}$ and $\mathrm{Cl} \mathrm{K \alpha} \mathrm{X}$-ray emission) and accompanying XANES spectra of a tarnish spot on the plate can be seen in Fig. 5. The tonal variations in the Ag XRF map show the changing distribution of $\mathrm{Ag}$ on the surface; the dark strands to the left of the tarnish spot indicate a relatively greater concentration of $\mathrm{Ag}$ while the lowest concentration is observed at the center of the tarnish feature. The decrease in Ag intensity at the center of the tarnish spot correlates to an increase in $\mathrm{Cl}$ and $\mathrm{S}$ signal. The $\mathrm{S} \mathrm{XRF}$ 

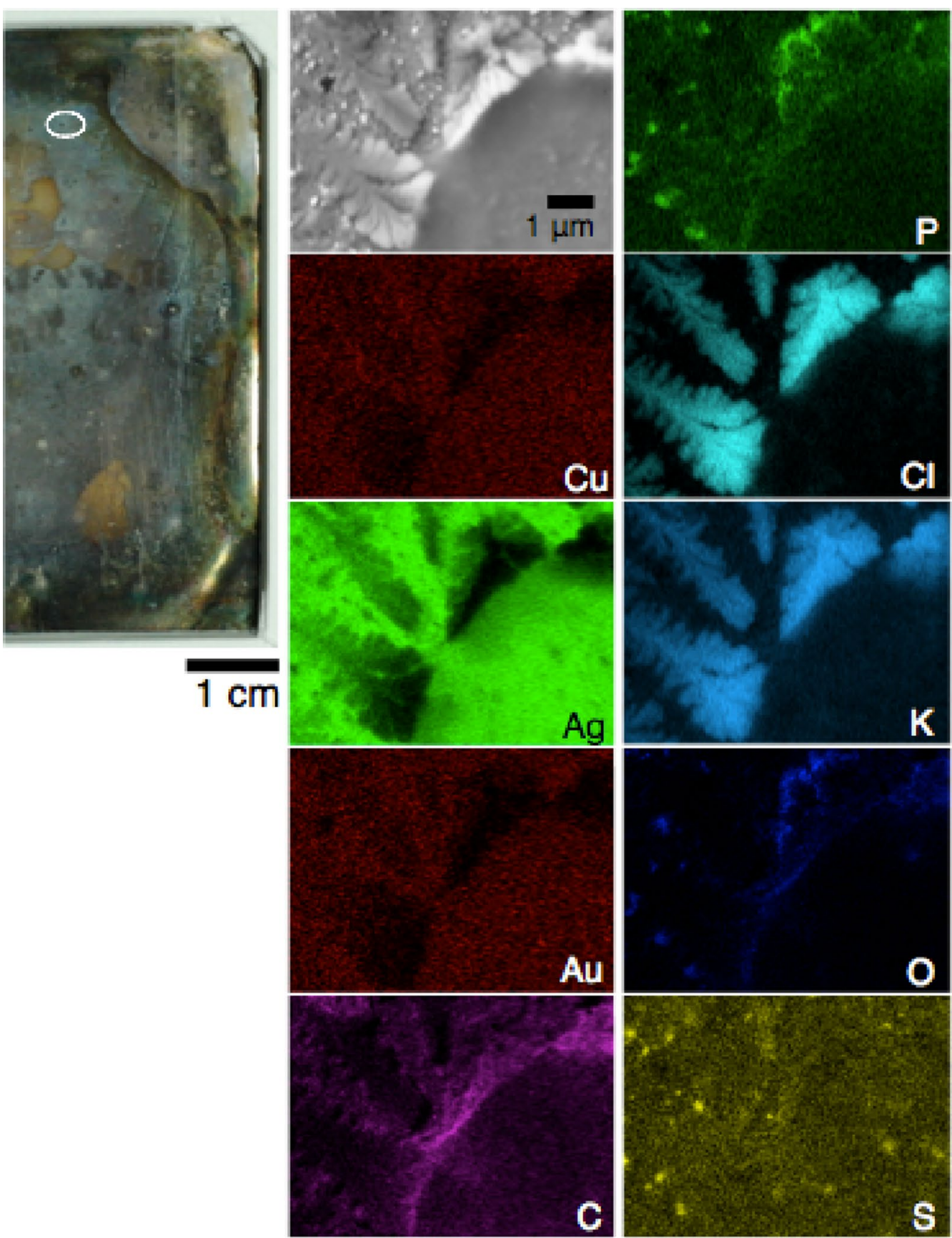

Fig. 4 EDX maps of tarnish spot. Maximum elemental concentration represented with greatest colour intensity, minimum concentration as black

shows decreased concentrations along the exterior of the of the woman's face.

The Ag $\mathrm{L}_{3}$-edge (Fig. 5), which arises from the excitation of a $2 \mathrm{p}_{3 / 2}$ electron to unoccupied bands above the Fermi level, displays no sharp peak at the edge (3351 eV) indicating a full $\mathrm{Ag} \mathrm{d}$ band. The subsequent oscillations are indicative of a face centered cubic (fcc) structure of Ag metal [26, 27]. Spectra 1, 2, and 3 show little variation and most closely resemble the Ag standard. While the two outside spectra (Ag spectra 2 and 3) LCF results indicate a dominance of pure $\mathrm{Ag}$, an $\mathrm{AgAu}$ alloy, and $\mathrm{Ag}_{2} \mathrm{~S}$. The presence of $\mathrm{AgCl}$, $\mathrm{AgBr}$, and $\mathrm{AgI}$ in all three regions is probable but not conclusive. 

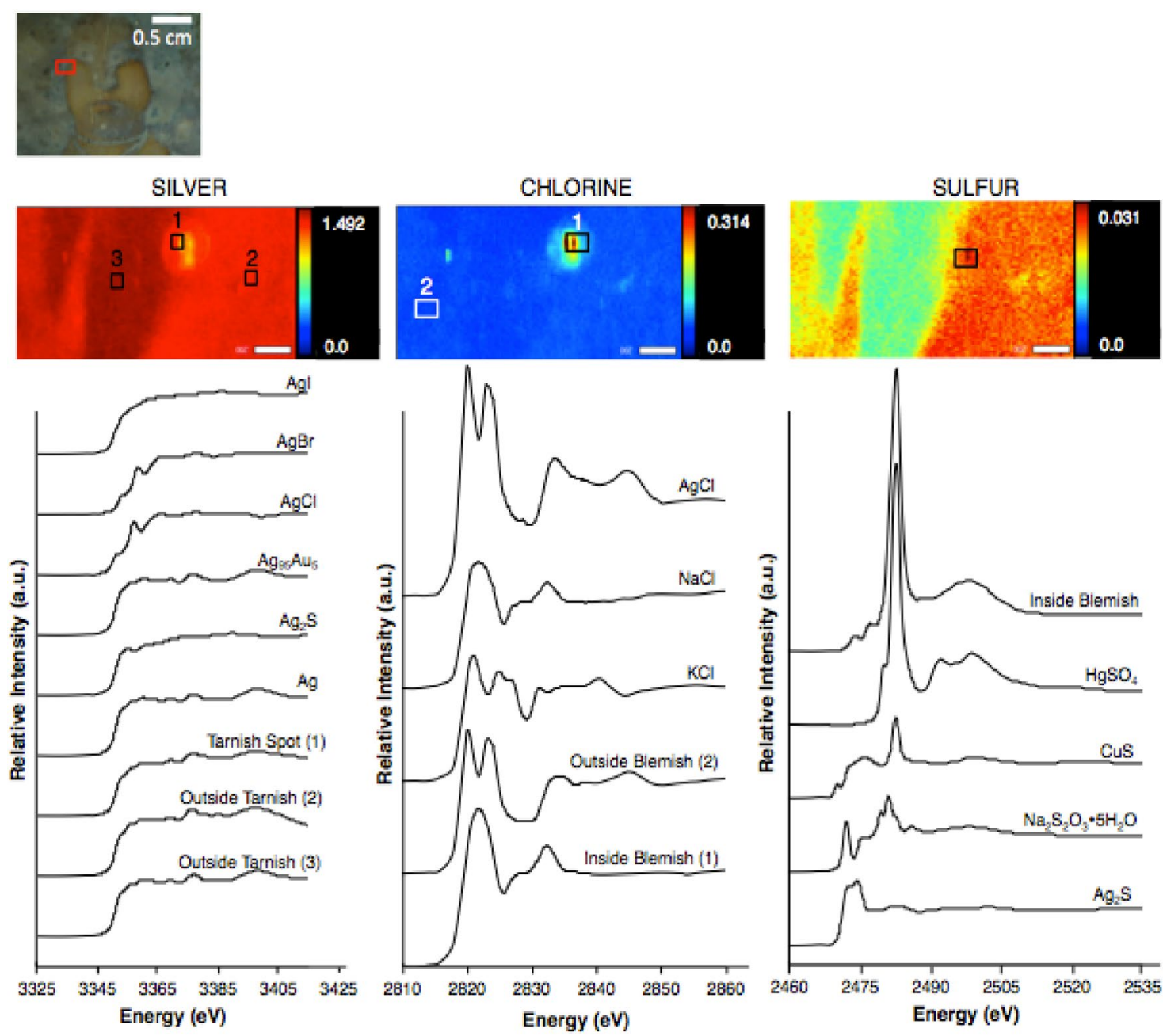

Fig. 5 XRF and micro-XANES at a blemish. Not all standards included for clarity. Space bar equals $200 \mu \mathrm{m}$

The Cl XRF image (Fig. 5) does not follow the elemental distribution found in $\mathrm{Ag}$ and $\mathrm{S}$. The greatest intensity of $\mathrm{Cl}$ was found at the center of the blemish with a lower, essentially uniform distribution throughout the rest of the image, which corresponds to the haze that is observed in the optical images. The $\mathrm{Cl}$ K-edge, which represents the excitation of an electron from a $1 s$ orbital to a previously unoccupied $3 p$ orbital, taken outside of the blemish spot matches that of the $\mathrm{AgCl}$ standard and EDX was used to detect the presence of $\mathrm{Ag}$ and $\mathrm{Cl}$. Silver chloride is commonly detected as a white haze that evenly covers the daguerreian image [6]. The majority of the signal within the blemish originates from $\mathrm{NaCl}$, an observation confirmed by the micro-XANES standard. This is corroborated with the LCF analysis (Additional file 2: Tables). In the surrounding region, $\mathrm{HgCl}_{2}, \mathrm{NaCl}$, $\mathrm{KCl}$, and $\mathrm{AgCl}$, were noted to be present through LCF analysis. The presence of $\mathrm{KCl}$ and $\mathrm{NaCl}$ at the center of the tarnish spot could be a result of the migration of $\mathrm{Na}^{+}$ and $\mathrm{K}^{+}$to from the cover glass surface through an ionexchange reaction by hydrogen ions (Eq. 1), resulting in $\mathrm{Na}^{+}$and $\mathrm{K}^{+}$precipitation onto the daguerreian surface $[13,14,28]$.

$$
\begin{gathered}
-\mathrm{SiO}-\mathrm{Na}^{+} / \mathrm{K}^{+}+\left(\mathrm{H}^{+}+\mathrm{OH}^{-}\right) \\
\rightarrow-\mathrm{SiOH}^{-}+\mathrm{Na}^{+} / \mathrm{K}^{+}+\mathrm{OH}^{-} .
\end{gathered}
$$

Given the contained environment in which the daguerreotype would have been held, there was most likely an active and ongoing exchange between the daguerreotype surface and the cover glass. Although environmental contamination should also be considered [4, p. 175], the effects of such contaminants are expected to be minimal in this case, on the basis of the 
typical indoor concentrations for $\mathrm{S}$ and $\mathrm{Cl}$ as well as the daguerreotype being contained within an enclosed environment. As this daguerreotype was removed from its case for an unknown period of time (prior to being acquired by the NGC), exposure to the environment could play a larger role in the degradation of the surface. Any contamination from indoor air would depend both on $\mathrm{S}$ and $\mathrm{Cl}$ concentrations in the air and the time of exposure. Long exposure to low concentrations of $\mathrm{S}$ and $\mathrm{Cl}$ might be expected to generate the effects observed in this report. Examples of typical indoor (i.e. museums) concentrations include $\mathrm{H}_{2} \mathrm{~S}(0.3 \mathrm{ppb})$, $\mathrm{COS}(0.6 \mathrm{ppb}), \mathrm{SO}_{2}$ (30 ppb), $\mathrm{HCl}\left(0.4 \mathrm{ppb}\right.$ ), and $\mathrm{Cl}_{2}$ (not detected) [29-32] with the deposition rate of indoor atmospheric particles to be $4 \mathrm{ng} / \mathrm{m}^{3}$ for $\mathrm{Cl}^{-}$and $720 \mathrm{ng} / \mathrm{m}^{3}$ for $\mathrm{SO}_{4}^{2-}$ [33]. These values should be considered as representative concentrations and will vary depending on the environment.

Only one location for the S K-edge XANES is reported (Fig. 5), as the counts were too low to collect a spectrum in other regions of the map. The primary inflection point for the absorption spectrum collected at the blemish center occurs at $2482.7 \mathrm{eV}$ with a post edge absorption feature at $2499.2 \mathrm{eV}$ [34]. Compared to standards with LCF analysis, the principal contribution is solely from $\mathrm{SO}_{4}^{2-}$, with the characteristic resonance at $\sim 2487 \mathrm{eV}$. The presence of residual sulfate ions is common on the surface of any $\mathrm{S}$ containing compounds of lower oxidation states. It may also be the result of cover glass deterioration as sulfate complexes have been established as a common degradation product [12].

Bubbles were observed at multiple locations on the daguerreotype; one example is shown in Fig. 6. This location shows a cluster of bubbles that are enclosed by a darkened circular band. Small image particles are observed above the circle, suggesting the presence of a precipitate. Although conservators have informally noted bubbles on the daguerreian surface and have attributed their presence as a product of "weeping glass" [4, p. 175, $12,35]$, their presence has not been discussed in depth in the literature. While there is no direct notion of cover glass corrosion leading to these particular surface features on the daguerreotype surface, sticky droplets on the inner surface of daguerreotype cover glasses are often observed [4, p. 175, 12].
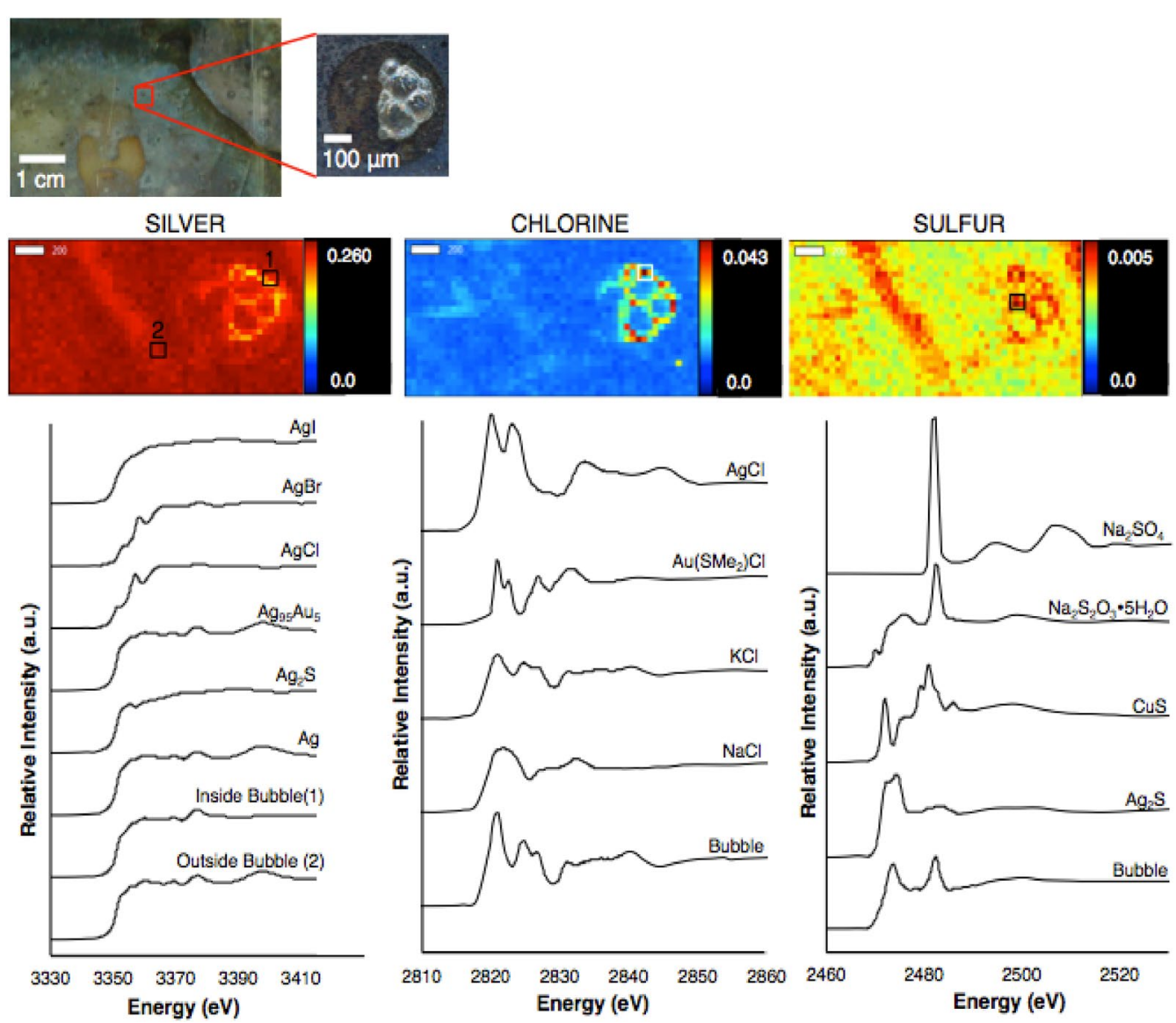

Fig. 6 XRF and micro-XANES of bubble. Not all standards included for clarity. Space bar equals $200 \mu \mathrm{m}$ 
The bubble is primarily comprised of $\mathrm{Cl}$ and $\mathrm{S}$, with hotspots of $\mathrm{S}$ observed outside of the bubble, where the precipitate products are observed in the optical image (Fig. 6). The S XRF also shows a concentrated band that inversely correlates to a band in the Ag XRF map.

The Ag $\mathrm{L}_{3}$-edge XANES of this bubble shows similar results to those in Fig. 6, where the majority of the signal is impacted by the Ag substrate. There is no sharp peak at the rising edge, indicating that the Ag d band is full. Metals with partially filled d bands always exhibit an intense resonance, historically called the whiteline [36]. While the white line is absent in the two $\mathrm{Ag} \mathrm{L}_{3}$-edge spectra, the absorption bands are weaker in comparison to the $\mathrm{Ag}$ standard; this is a result of $s-d$ hybridization. As the area under the curve for the experimental spectra (regions 1 and 2) is decreased when compared to the Ag standard, the presence of an AgAu alloy is confirmed, a result of the gilding process. While the Ag absorption spectra primarily provide information on the AgAu alloy, collecting $\mathrm{S}$ and $\mathrm{Cl} \mathrm{K}$-edge XANES does provide information regarding the tarnish composition.

The $\mathrm{Cl}$ K-edge XANES (Fig. 6), with a threshold located at $2822 \mathrm{eV}$, was collected at a hotpot found within the bubble. While $\mathrm{AgCl}$ is often the primary $\mathrm{Cl}$ tarnish feature noted in literature [6], at this location it only accounts for $2.4 \mathrm{wt}$. \% of the signal. The major contributor to the $\mathrm{Cl} \mathrm{K}$-edge spectrum in Fig. 6 is from $\mathrm{KCl}$, which was estimated to be $97.6 \mathrm{wt}$. \%, of the experimental spectrum, by LCF analysis. Similar to the tarnish feature discussed in Fig. 5, this may be another example of $\mathrm{K}^{+}$ ion migration from the corroding cover class glass that is then deposited on the daguerreian surface [37].

The S K-edge is comprised of two major composite peaks at approximately 2473 and $2483 \mathrm{eV}$ (Fig. 6), which arises from a $1 s \rightarrow 3 p$ transition. The location of this first transition doublet suggests that the $\mathrm{S} p \pi *$ orbital is directly involved in the covalent $\mathrm{Ag}-\mathrm{S}$ interaction [38]. This metal-sulfur bond is seen as the double feature of the first peak [39]. Differing from those shown in Figs. 5 and 7 (see below), the feature at $2473 \mathrm{eV}$ shows a single peak. The second peak at about $2482 \mathrm{eV}$ corresponds to the oxidized form of sulfur $\left(\mathrm{SO}_{4}^{2-}\right.$, characteristic $\sigma^{*}$ multiple scattering in a $t_{d}$ environment) [40]. The relative weight percent determined from LCF analysis of the experimental spectrum was estimated to be 6.7 and 49.9 from $\mathrm{SO}_{4}^{2-}(6+)$ and $\mathrm{S}^{-2}(2-)$, respectively. The LCF analysis revealed approximately 43.4 wt. \% to be from $\mathrm{CuS}$. The presence of $\mathrm{Cu}$ on the surface may also be a result of $\mathrm{Cu}$ diffusing through grain boundaries and/or holes in the $\mathrm{Ag}$, as Marquis have previously noted $\mathrm{Cu}$ on the Ag surface [41]. Crystalline $\mathrm{Cu}$ salts have been reported on the surface of daguerreotypes [25, 41] and the accretion of $\mathrm{Cu}$ salts, such as basic sodium copper carbonate
$\left(\mathrm{Na}_{3}\left[\mathrm{Cu}_{2}\left(\mathrm{CO}_{3}\right)_{3}(\mathrm{OH})\right] \cdot 4 \mathrm{H}_{2} \mathrm{O}\right)$, has been noted by Barger and White [4, p. 167] as a result of cover glass deterioration. Other studies have also reported that glass corrosion can produce copper oxides and copper sulfides [19, 24, 41, 42]. The LCF analysis should be taken as semiquantitative at best, since non-uniform distribution of substances and varying penetration depth of the photon will contribute to the uncertainty.

The tarnish spot located on the right side of the daguerreotype (Fig. 7) shows a central, flat blemish encircled by a green ring, followed by a yellow halo. The entire feature is surrounded by blue tinted ring (optical image supplied in Fig. 3; top center). A precipitate is observed on the surrounding ring. The Ag XRF map reveals an even distribution of $\mathrm{Ag}$ across the image except for a sharp decrease in concentration at the center of the tarnish feature as well as a slight decrease in intensity where the blue band encircles the blemish. The $\mathrm{Cl}$ XRF image shows the center of the blemish has the greatest amount of $\mathrm{Cl}$ with a slight increase in concentration of $\mathrm{Cl}$ along the exterior. Similar concentrations of S are observed in the outer-most ring of the feature that correlates with the visibly darker degradation products seen in the optical image, attributed to $S$ accumulation [5].

Similar to the $\mathrm{Ag} \mathrm{L}_{3}$-edge XANES collected at the other tarnish locations (Figs. 5, 6), the absorption regions 1 and 2 indicate the dominance of the Ag substrate. The decreased area under the curve, when compared to the Ag standard, indicates a small concentration of $\mathrm{Au}$ alloyed with Ag since the appearance of the Ag XANES is clearly $\mathrm{AgAu}$ alloy-like [43]. Both $\mathrm{AgCl}$ and $\mathrm{AgI}$ were detected with LCF analysis outside of the tarnish location.

The location of the $\mathrm{Cl}$ K-edge jumps (Fig. 7) in both spectra and the subsequent oscillations, match those of the $\mathrm{AgCl}$ standard. Like the other examined locations, $\mathrm{NaCl}$ and $\mathrm{KCl}$ were also detected, pointing to cover glass deterioration as a source for the degradation spot. While LCF analysis also noted the presence of $\mathrm{HgCl}_{2}$, which may be due to residual halide that was trapped in the substrate binding to $\mathrm{Hg}$ during plate "fixing", the reported amounts do not provide substantial evidence.

Only one S K-edge was collected due to low counts of S on the perimeter of the blemish. The threshold resonance of the $\mathrm{S}$ K-edge is due to the transition of a $1 s$ electron to $p$-like states in the conduction band. The XANES intensity maximum of the disulfide is almost a factor of 3 less than that of $\mathrm{SO}_{4}^{2-}$; this is not unexpected since $p$ densities of states are depleted in the highly oxidized $S$ [44]. Linear combination fit results indicate the experimental spectrum to be comprised of 20.2 wt. $\% \mathrm{HgSO}_{4}, 4.3$ wt. $\% \mathrm{Na}_{2} \mathrm{SO}_{4}, 58.8$ wt. $\% \mathrm{Ag}_{2} \mathrm{~S}$, and 16.8 wt. \% thiosulfate. The presence of multiple forms of sulfur points to a 

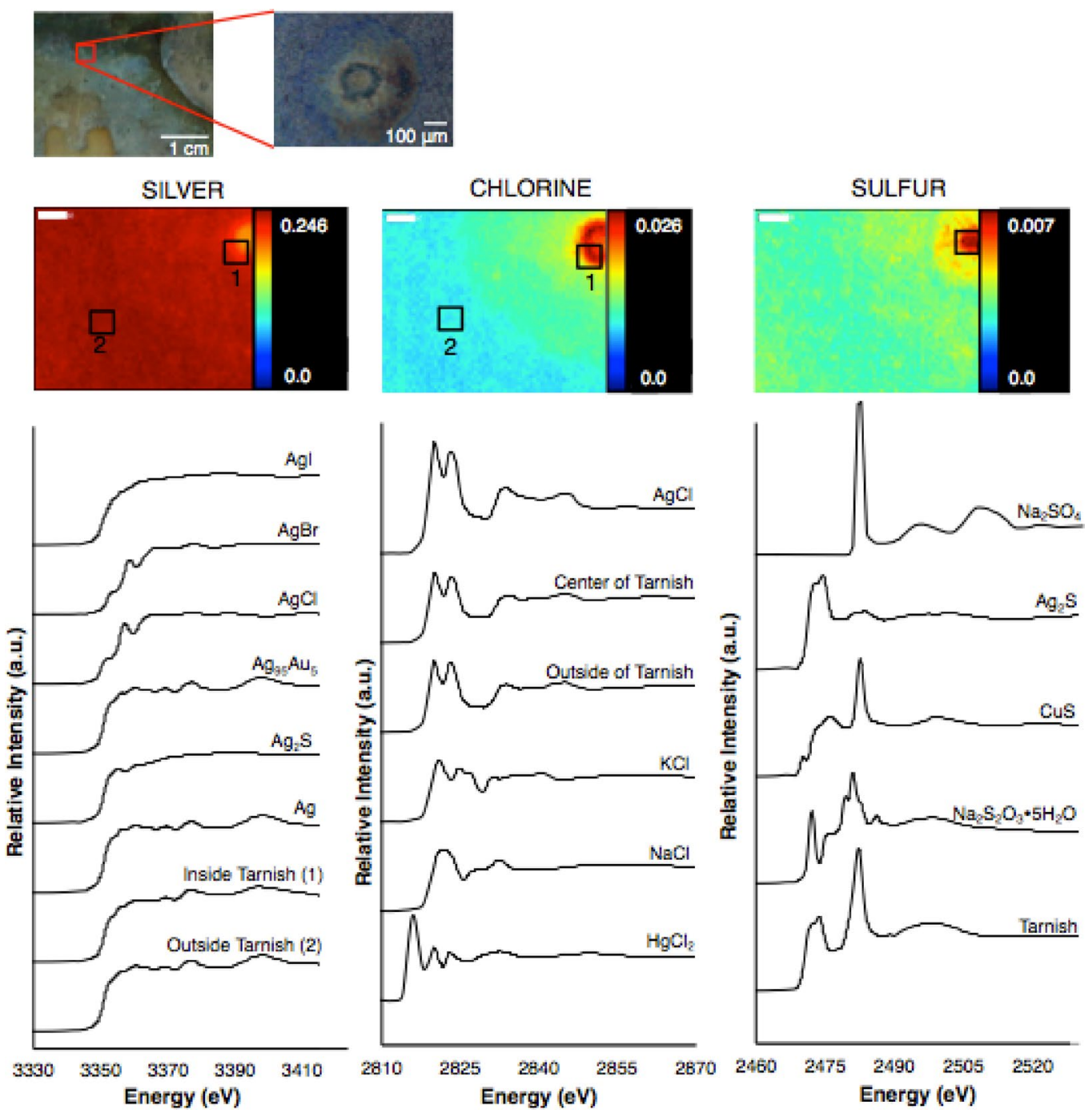

Fig. 7 XRF and micro-XANES of tarnish spot. Not all standards included for clarity. Space bar equals $60 \mu \mathrm{m}$

complicated degradation process that occurs within the daguerreian system.

\section{Conclusions}

Tarnished daguerreotypes were examined here using synchrotron XANES and XRF analysis. Synchrotron XRF showed that the distributions of $\mathrm{Ag}$ and $\mathrm{S}$ were inversely correlated, suggesting a preferential accumulation of $\mathrm{S}$ within high-density particle regions. While $\mathrm{Ag}_{2} \mathrm{~S}$ and $\mathrm{SO}_{4}^{2-}$ were observed as primary sulfur degradation products, $\mathrm{S}$ K-edge examination of regions on, and surrounding, the tarnish features indicated the presence of $\mathrm{Hg}-\mathrm{S}$ interactions in the form of $\mathrm{HgS}$ and $\mathrm{HgSO}_{4}$. XANES analysis at the $\mathrm{Ag} \mathrm{L}_{3}$-edge found residual silver halides at multiple locations, suggesting they remain embedded in the Ag substrate. Atmospheric contamination is also a viable pathway for $\mathrm{Cl}$ to accumulate on the daguerreian surface. These results are in agreement with and go beyond what SEM-EDX analysis can provide. The results of this study revealed that cover glass deterioration may initiate a variety of, but not all, tarnish features. Future analysis will include the analysis of the $\mathrm{Hg}$ absorption edge to gain a greater understanding of the $\mathrm{Hg}$ chemistry on the plate.

Factors such as the original production and washing procedures, the storage environment and atmospheric conditions, and the possibility of previous conservation efforts will impact the integrity of the image. Clearly, these decomposition products make extremely complex tarnish substances on the surface, suggesting that the 
corrosion process is a result of multiple factors, including cover glass deterioration caused by complex interactions between the daguerreotype surface and the glass. It is suggested that the glass be examined and replaced and/or preserved prior to daguerreian display or storage, no matter the condition of the plate. Furthermore, cover glass longevity should be the primary point of scrutiny when selecting new modes of daguerreotype display [45]. Glass that inhibits the admittance of certain wavelengths from the exhibition space onto the daguerreotype surface may promote the longevity and reduce future hazing of these historic images [46]. Further studies need to be conducted to select the appropriate glass materials to ensure safe, long-term protection of these valuable 19th century images.

\section{Additional files}

Additional file 1: FigureS1. Example of absorption spectrum (bubble from Fig. 6) with the corresponding linear combination fit (LCF) and difference (Diff.) spectra for the $\mathrm{Ag}_{3}$-edge. The difference spectrum is indicative of the error of measurement for the spectrum.

Additional file 2: Table S1. Linear combination fit results for $\mathrm{Cl}$ K-edge XANES spectra (values in weight percent). Table 2. Linear combination fit results for S K-edge XANES spectra (values in weight percent). Table 3. Linear combination fit results for $\mathrm{Ag}_{\mathrm{L}}$-edge XANES spectra (values in weight percent)

\section{Authors' contributions}

MSK performed synchrotron data collection, analysis, and production of the manuscript draft with the assistance of TKS on data interpretation. MSK, TKS, RRM, and AJN contributed to the manuscript. All authors read and approved the final manuscript.

\section{Author details}

${ }^{1}$ The Department of Chemistry, The University of Western Ontario, 1151 Richmond Street, London, ON N6A 5B7, Canada. ${ }^{2}$ The Department of Anthropology, The University of Western Ontario, 1151 Richmond Street, London, ON N6A 5C2, Canada. ${ }^{3}$ Canadian Light Source Inc., 44 Innovation Blvd, Saskatoon, SK S7N 2V3, Canada.

\section{Acknowledgements}

This work was made possible through the generous collaboration with John McElhone of the Canadian Photography Institute at the National Gallery of Canada. Scanning electron microscopy images were collected with the assistance of Todd Simpson, Western Nanofabrication Laboratory, Western University. Digital optical microscopy images with the Leica LAS-X were collected with the assistance of the Wren Research Group, Department of chemistry, Western University. Synchrotron experiments were performed at the Canadian Light Source with the technical assistance of the Beamline Staff, Dr. Yongfeng Hu and Dr. Qunfeng Xiao.

\section{Competing interests}

All authors declare that they have no competing interests.

\section{Declarations}

We confirm that this work is original and has not been published elsewhere, nor is it currently under consideration for publication elsewhere.

\section{Ethics approval and consent to participate:}

Not applicable.

\section{Funding}

This research was supported by the National Science and Engineering Research Council of Canada, the Canadian Foundation for Innovation, Canada Research Chairs (TKS) and the Ontario Ministry of Innovation. Further support for interdisciplinary research was provided by The Dean's Office, Faculty of Science at The University of Western Ontario. Synchrotron experiments, which were conducted at the Canadian Light Source, are supported by NSERC, NRC, $\mathrm{CIHR}$ and the University of Saskatchewan.

\section{Publisher's Note}

Springer Nature remains neutral with regard to jurisdictional claims in published maps and institutional affiliations.

Received: 6 November 2017 Accepted: 4 February 2018

Published online: 06 March 2018

\section{References}

1. Da Silva E, Robinson M, Evans C, Pejovic-Milic A, Heyd DF. Monitoring the photographic process, degradation and restoration of 21st century Daguerreotypes by wavelength-dispersive X-ray fluorescence spectrometry. J Anal Atom Spectrosc. 2010;25:654-61.

2. Robinson M. The techniques and material aesthetics of the daguerreotype. Leicester: De Montfort University; 2017 (Doctor of philosophy in photographic history dissertation).

3. Motoyoshi I, Nishida S, Sharan L, Adelson EH. Images statistics and the perception of surface qualities. Nature. 2007:446:206-9.

4. Barger SM, White WB. The daguerreotype: nineteenth century technology and modern science. Washington: Smithsonian Institution Press; 1991. p. 120-215.

5. Barger SM, Krishnaswamy SV, Messier R. The cleaning of daguerreotypes: comparison of cleaning methods. J Am Inst Conserv. 1982;22:13-24.

6. Centeno SA, Schulte F, Kennedy NW, Schrott AG. The formation of chlorine-induced alterations in daguerreotype image particles: a high resolution SEM-EDS study. Appl Phys A. 2011;105:55-63.

7. Barger SM, Messier R, White WB. A physical model for the daguerreotype. Photogr Sci Eng. 1982;26:285-91.

8. Ravines P. Characterization of the daguerreotype using the surface metrology instrumental technique of confocal scanning disk microscopy. Am Lab. 2010;42:20-5.

9. Anglos D, Melesanaki K, Zafiropulos V, Gresalfi MJ, Miller JC. Laser-induced breakdown spectroscopy for the analysis of 150-year-old daguerreotypes. Appl Spectrosc. 2002;56:423-32

10. Hogan DL, Golovlev VV, Gresalfi MJ, Chaney JA, Feigerie CS, Miller JC, Romer G, Messier P. Laser ablation mass spectroscopy of nineteenth century daguerreotypes. Appl Spectrosc. 1999;53:1161-8.

11. Kozachuk MS, Martin RR, Sham TK, Robinson M, Nelson AJ. The application of XANES for the examination of silver, gold, mercury, and sulfur on the daguerreotype surface. Can J Chem. 2017;95:1156-62.

12. Barger SM. Characterization of corrosion products on old protective glass, especially daguerreotype cover glasses. J Mat Sci. 1989;24:1343-56.

13. Wagner B, Nowak A, Bulska E, Kunicki-Goldfiner J, Schalm O, Janssens K. Complementary analysis of historical glass by scanning electron microscopy with energy dispersive X-ray spectroscopy and laser ablation inductively coupled plasma mass spectrometry. Microchim Acta. 2008:162:415-24.

14. McPhail DS. Applications of secondary ion mass spectrometry (SIMS) in materials science. J Mater Sci. 2006:41:873-903.

15. Choudhury S, Hormes J, Agyeman-Budu DN, Woll AR, George GN, Coulthard I, Pickering IJ. Application of a spoked channel array to confocal X-ray fluorescence imaging and X-ray absorption spectroscopy of medieval stain glass. J Anal At Spectrom. 2015;30:759-66.

16. Caley ER. Analyses of ancient glasses 1790-1957. A comprehensive and critical survey, monographs, vol. 1. NY: The Coming Museum of Glass, Corning; 1962

17. Hu YF, Coulthard I, Chevrier D, Wright G, Igarashi R, Sitnikov A, Yates BW, Hallin EL, Sham TK, Reininger R. Preliminary commissioning and 
performance of the soft $\mathrm{X}$-ray micro-characterization beamline at the canadian light source. AIP Proc Int Conf Synchrotron Radiat Instrum. 2010;1234:343.

18. Ravel B, Newville M. ATHENA, ARTEMIS, HEPHAESTUS: data analysis for X-ray absorption spectroscopy using IFEFFIT. J Synchrotron Radiat. 2005;12:537-41.

19. Ravel B. Athena user's guide. The University of Chicago. 2009. http://cars9. uchicago.edu/ ravel/software/exafs/. Accessed 10 Sept 2014.

20. Webb SM. The microanalysis toolkit: $X$-ray fluorescence image processing software. AIP Conf Proc. 2011;1365:196-9.

21. Rueden C, Dietz C, Horn M, Schindelin J, Northan B, Berthold M, Eliceiri K. 2016. ImageJ Ops [Software]. http://imagej.net/Ops. Accessed 24 July 2017.

22. Ravines P, Wiegandt R, Wichern CM, Hailstone R, Romer G. The application of optical and surface metrology to daguerreotypes. Topics Photogr Preserv. 2007;12:211-23.

23. Robinet L, Pulham C, Hall C, Eremin K, Fearn S. Understanding glass deterioration in museum collections through SIMS analysis. MRS online proceeding library archive. 2011. https://doi.org/10.1557/PROC-852-008.8.

24. Nicholson ME. Electronic packaging and corrosion in microelectronics. Metals Park: ASM International; 1987. p. 237.

25. Swan A, Fiori CE, Heinrich KFJ. Daguerreotypes: a study of the plates and the process. Scan Electron Micros. 1979;1:411-24.

26. Bovenkamp GL, Zanzen U, Krishna KS, Hormes L, Prange A. X-ray absorption near-edge structure (XANES) spectroscopy study of the interaction of silver ions with Staphylococcus aureus, Listeria monocytogenes, and Escherichia coli. Appl Environ Microb. 2013;79:6385-90.

27. Bzowski A, Sham TK, Yiu YM. Charge redistribution in Au-metalloid intermetallics: a Au $\mathrm{L}_{2,3} \mathrm{X}$-ray absorption study. Anal Review B. 1994;49:9515-20

28. Papadopoulos N, Drosou CA. Influence of weather conditions on glass properties. J Chem Technol Metall. 2012;7:429-39.

29. Graedel TE, Hawkins IT, Claxton LD. Atmospheric chemical compounds: sources, occurrence, and bioassay. 1st ed. Orlando: Academic Press; 1896.

30. Yocom JE, Clink WL, Cote WA. Indoor-outdoor air quality relationships. J Air Pollut Control Assoc. 1971;21:251-9.

31. Hackney $\mathrm{S}$. The distribution of gaseous air pollution within museums. Stud Conserv. 1984;29:105-16.

32. Hisham MWM, Grosjean D. Sulfur dioxide, hydrogen sulfide, total reduced sulfur, chlorinated hydrocarbons and photochemical oxidants in southern California museums. Environ Set Technol. 1991;25:1497-505.
33. Sinclair JD, Psota-Kclty LA, Weschler CJ. Indoor/outdoor ratios and indoor surface accumulations of ionic substances at Newark, New Jersey. Atmos Environ. 1988:22:461-9.

34. Serrano S, Vlassopoulos D, Bessinger B, O'Day PA. Immobilization of $\mathrm{Hg}$ (II) by coprecipitation in sulfate-cement systems. Environ Sci Technol. 2012;46:6767-75

35. Humphrey SD. American hand book of the daquerreotype: giving the most approved and convenient methods for preparing the chemicals, and the combinations used in the art. Containing the daquerreotype, electrotype, and various other processes employed in taking heliographic impression. 5th ed. New York: 1858.

36. Penner-Hahn JE. X-ray absorption spectroscopy. eLS. 2005;174. https:// doi.org/10.1038/npg.els.0002984.

37. Huggins FE, Huffman GP. Chlorine in coal: an XAFS spectroscopic investigation. Fuel. 1995;74:556-69.

38. Fleet ME. XANES spectroscopy of sulphur in Earth materials. Can Min. 2005;43:1811-38

39. van Hullebusch E, Rossano S, Farges F, Lenz M, Labanowski J, Lagarde P, Flank A-M, Lens P. Sulfur K-edge XANES spectroscopy as a tool for understanding sulfur dynamics in soil organic matter. J Phys Conf Ser. 2009;190:12184.

40. Manceau A, Nagy KL. Quantitative analysis of sulfur functional groups in natural organic matter by XANES spectroscopy. Geochim Cosmochim Acta. 2012;99:206-23.

41. Marquis EA, Chen Y, Kohanek J, Dong Y, Centeno SA. Exposing the subsurface of historical daguerreotypes and the effects of sulfur-induced corrosion. Corros Sci. 2015;94:438-44.

42. Swan A. The preservation of daguerreotypes. In: Norris DH, Gutierrez JJ, editors. Issues in the conservation of photographs. Los Angeles: Getty Conservation Institute; 2010. p. 255.

43. Tyson CC, Bzowski A, Kristof P, Kuhn M, Sammynaiken R, Sham TK. Charge redistribution in Au-Ag alloys from a local perspective. Phy Rev B Condens Matter. 1992:45:8924-8.

44. Sandström M, Jalilehvand F, Persson I, Gelius U, Frank P, Hall-Roth I. Deterioration of the seventeenth-century warship Vasa by internal formation of sulphuric acid. Nature. 2002;415:893-7.

45. Tru Vue, Inc. Netwise data. Illinois: Boca Ration; 2016.

46. Dunnill CW. UV blocking glass: low cost filters for visible light photocatalytic assessment. J Photoenerg. 2014;2014:1-5.

\section{Submit your manuscript to a SpringerOpen ${ }^{\circ}$ journal and benefit from:}

- Convenient online submission

- Rigorous peer review

- Open access: articles freely available online

- High visibility within the field

- Retaining the copyright to your article

Submit your next manuscript at $\boldsymbol{\nabla}$ springeropen.com 